\title{
Burkitt Lymphoma Mimicking as Pancreas Adenocancer With Liver Metastases
}

\author{
Banu Kara ${ }^{\text {a, d }}$, Mehmet Suat Yalcin ${ }^{\mathrm{a}}$, Huseyin S. Bozkurt ${ }^{\mathrm{b}}$, \\ Emine Kilic Bagirc
}

\begin{abstract}
Primary lymphomas of the pancreas are uncommon and Burkitt lymphoma (BL) involving pancreas is very rare. It is important to recognize this entity because it can resemble adenocarcinoma of the pancreas but its management is entirely different. We describe a case of synchronous pancreatic, duedonal and liver involvement of BL in a 34-year-old man who presented with acute pancreatitis. Abdominal computed tomography revealed a hypoechogenic area within the head of the pancreas and multiple hypoechogenic areas in the liver. Upper gastrointestinal (GI) endoscopy revealed multiple ulcerated polypoid lesions in the duodenum. Percutaneous fine-needle aspiration biopsy of the liver lesions and endoscopic biopsy of duedonal lesions revealed BL. This is an unusual presentation of BL with pancreatic, duedonal and liver involvement which mimicks as pancreas adenocarcinoma with liver and duedonal metastases.
\end{abstract}

Keywords: Acute pancreatitis; Burkitt lymphoma

\section{Introduction}

Non-Hodgkin's lymphoma (NHL) frequently arises in extranodal sites, with about $50 \%$ of patients having extranodal involvement [1]. The gastrointestinal (GI) tract is the most frequent site seen, with the stomach and intestines being involved in most cases. Clinical features are often non-specific and therefore diagnosis is sometimes delayed. Non-specific abdominal pain $(50 \%)$ and dyspepsia $(30 \%)$ are the most common symptoms [2]. Pancreatic tumors such as adeno-

Manuscript submitted August 26, 2017, accepted September 18, 2017

${ }^{a}$ Clinic of Gastroenterology, Adana Numune Research and Education Hospital, University of Health Sciences, Adana, Turkey

${ }^{b}$ Clinic of Gastroenterology, Medical Park Private Tarsus Hospital, Mersin, Turkey

'Pathology Department, Faculty of Medicine, Cukurova University, Adana, Turkey

${ }^{\mathrm{d} C o r r e s p o n d i n g ~ A u t h o r: ~ B a n u ~ K a r a, ~ G a s t r o e n t e r o l o g y ~ D e p a r t m e n t, ~ A d a n a ~}$ Numune Education and Research Hospital, Yuregir, Adana 01240, Turkey. Email: banu.banu97@gmail.com

doi: https://doi.org/10.14740/jmc2899w carcinoma, pancreatic lymphoma and metastases have been implicated in causation of acute pancreatitis and account for $1-2 \%$ of cases of acute pancreatitis [3]. This case is being presented in view of its rarity and to alert the clinicians to consider underlying lymphoma in unexplained cases of acute pancreatitis.

\section{Case Report}

The patient was a 34-year-old man with no history of alcoholism, biliary lithiasis and drug consumption. He was admitted with acute-onset epigastric pain and vomiting. The biochemical results were: WBC count, $11,800 / \mu \mathrm{L}$; hemoglobin level, $15.3 \mathrm{~g} / \mathrm{dL}$; AST, $34 \mathrm{IU} / \mathrm{L} ;$ ALT, $30 \mathrm{IU} / \mathrm{L}$; total bilirubin level, $0.58 \mathrm{mg} / \mathrm{dL}$; lactate dehydrogenase, 1,156 IU/L (reference range, 250 - $580 \mathrm{IU} / \mathrm{L}$ ); serum lipase, 1,851 U/L (reference range, 13 - $60 \mathrm{U} / \mathrm{L}$ ); serum amylase, $740 \mathrm{U} / \mathrm{L}$ (reference range, $28-100 \mathrm{U} / \mathrm{L}$ ). The abdominal computed tomography (CT) scan indicated a $2 \mathrm{~cm}$ diameter irregular solid lesion in the head of pancreas, suspicion of duedonal invasion and multiple hypoechoic liver lesions, suggesting an advanced pancreatic adnocarcinoma with liver metastases. No retroperitoneal and para-aortic lymph nodes were detected (Figs. 1 and 2). CA 19-9 was normal. Upper GI system endoscopy showed 5 - 6

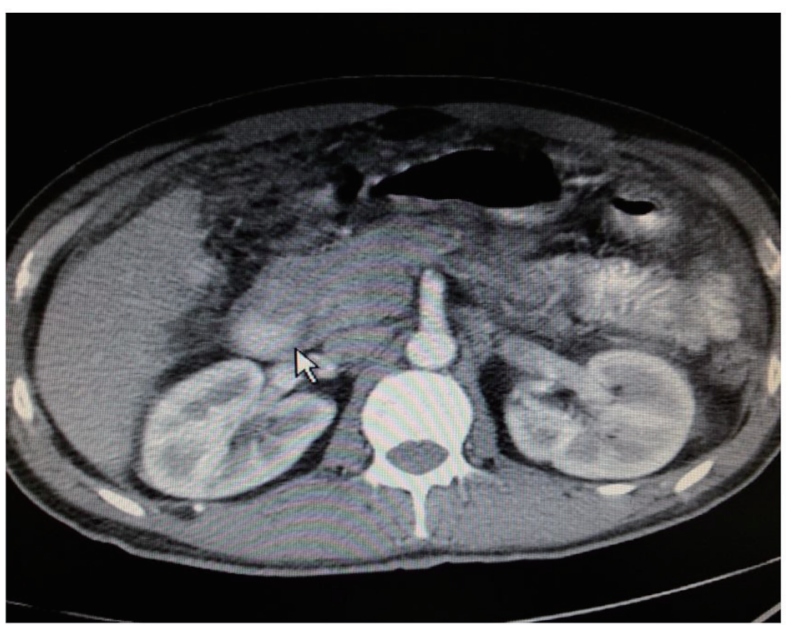

Figure 1. Contrast $\mathrm{CT}$ of abdomen showing mass in the region of the head of the pancreas. 


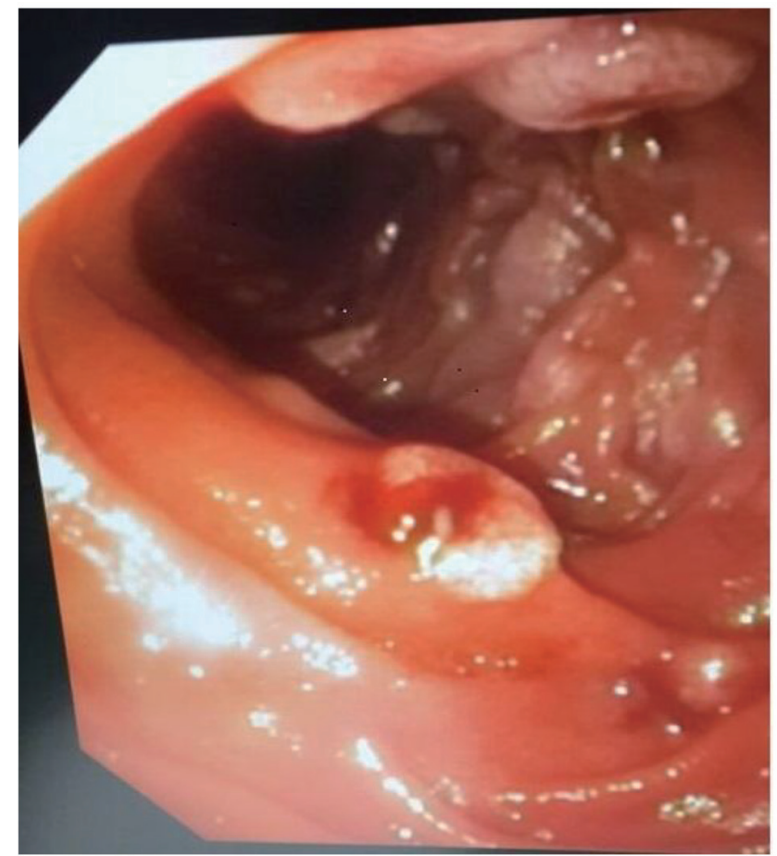

Figure 2. Upper gastrointestinal endoscopy showing multiple ulcerated polypoid lesions in the duodenum.

$\mathrm{mm}$ in diameter, polypoid and centrally ulcerated five lesions in the duedonum and biopsies of them were taken. Ultrasoundguided fine-needle biopsy of the hepatic lesions was taken too. The biopsies of both liver and duedonal lesions revealed Burkitt lymphoma (BL). Diffuse infiltration by large atypical lymhoid cells with increased mitotic activity was immunreactive for leukocyte common antigen, Bcl-6, CD10, and CD20 and negative for CD3, CD5 and Bcl-1. The Ki67 score was higher than $95 \%$ (Fig. 3).

\section{Discussion}

Malignant lymphoma infrequently involves the pancreas. The estimated frequency of primary NHL of the pancreas is about $2.2 \%$. Secondary pancreatic involvement by NHL is equally uncommon; approximately $0.2-2.2 \%$ of patients with NHL have pancreatic involvement at presentation [4]. Pancreatic involvement in lymphoma can be due to peripancreatic lymph node mass causing direct invasion of the parenchyma, intrinsic pancreatic mass lesion with or without discrete peripancreatic lymphadenopathy or secondary extranodal deposit [5]. Cases have been described in both pediatric and adult population, presenting with obstructive jaundice, pancreatitis or symptoms of gastric outlet obstruction. In older individuals with elevated CA 19-9 levels, BL can be mistaken for adenocarcinoma of the pancreas and they therefore undergo major surgery [6]. Imaging plays an important role in the diagnosis and staging of pancreatic masses. The well-circumscribed tumoral form is distinguished from pancreatic adenocarcinoma by the absence of pancreatic duct involvement and the presence of surrounding lymphadenopathy $[7,8]$. Ultrasound- or CT-guided fine-needle

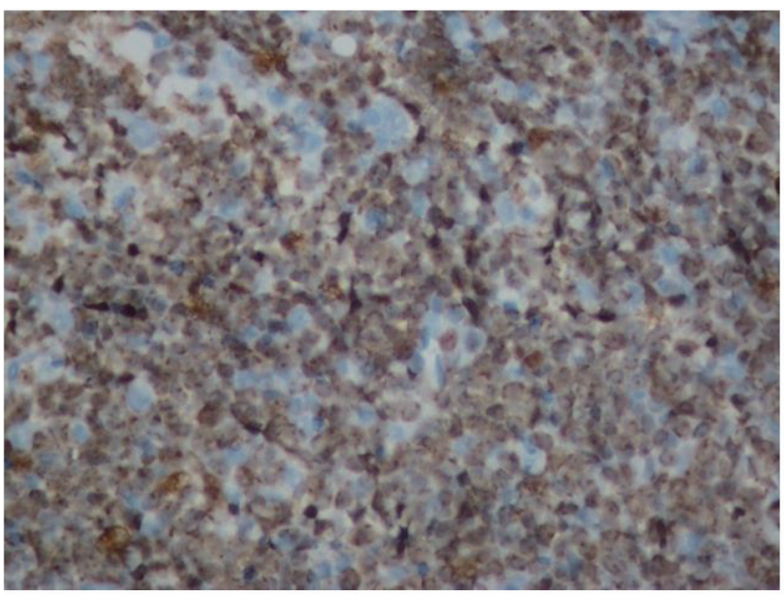

Figure 3. Increased mitotic activity shown by $>95 \%$ Ki67 positivity.

biopsy of the pancreatic mass helps to make differential diagnosis. When available, endoscopic ultrasound-guided fineneedle aspiration is an established first-line procedure in the management of solid and cystic pancreatic masses [9]. Acute pancreatitis as a complication of adenocarcinoma of pancreas is well described $[10,11]$. There are also few case reports of acute pancreatitis as initial presentation of nodal NHL[12, 13] and pancreatic lymphoma [2, 14].

This is an important case report emphasizing the importance of distinguishing pancreatic lymphoma from pancreatic carcinoma. Secondary involvement of the pancreas by B-cell lymphoma is a rare occurrence. It is important to include such secondary involvement in the differential diagnosis of patients that present with acute pancreatitis. Pathologic diagnosis is important in distinguishing pancreatic lymphoma from pancreatic carcinoma and appropriate evaluation can lead to early diagnosis and successful outcome as in our case.

\section{Conflict of Interest}

The authors have no potential conflict of interest.

\section{References}

1. Ghai S, Pattison J, Ghai S, O’Malley ME, Khalili K, Stephens M. Primary gastrointestinal lymphoma: spectrum of imaging findings with pathologic correlation. Radiographics. 2007;27(5):1371-1388.

2. Reddy D, Gumaste V, Benisovich V. Primary pancreatic lymphoma presenting as acute pancreatitis. Pancreatology. 2003;3(5):403-405.

3. Shanbhogue AK, Fasih N, Surabhi VR, Doherty GP, Shanbhogue DK, Sethi SK. A clinical and radiologic review of uncommon types and causes of pancreatitis. Radiographics. 2009;29(4):1003-1026.

4. Bernardeau M, Auroux J, Cavicchi M, Haioun C, Tsakiris L, Delchier JC. Secondary pancreatic involvement by diffuse large B-cell lymphoma presenting as acute 
pancreatitis: treatment and outcome. Pancreatology. 2002;2(4):427-430.

5. Ramesh J, Hebert-Magee S, Kim H, Trevino J, Varadarajulu S. Frequency of occurrence and characteristics of primary pancreatic lymphoma during endoscopic ultrasound guided fine needle aspiration: a retrospective study. Dig Liver Dis. 2014;46(5):470-473.

6. Nistala SS, Sawalakhe NR, Thiruvengadam NR, Rathi PM. A rare case of primary pancreatic Burkitt lymphoma in a young Indian male. Case report and review of the literature. JOP. 2009;10(6):686-689.

7. Merkle EM, Bender GN, Brambs HJ. Imaging findings in pancreatic lymphoma: differential aspects. AJR Am J Roentgenol. 2000;174(3):671-675.

8. Van Beers B, Lalonde L, Soyer P, Grandin C, Trigaux JP, De Ronde T, Dive C, et al. Dynamic CT in pancreatic lymphoma. J Comput Assist Tomogr. 1993;17(1):94-97.

9. Sadaf S, Loya A, Akhtar N, Yusuf MA. Role of endoscopic ultrasound-guided-fine needle aspiration biopsy in the diagnosis of lymphoma of the pancreas: A clinicopathological study of nine cases. Cytopathology. 2017.

10. Gambill EE. Pancreatitis associated with pancreatic carcinoma: a study of 26 cases. Mayo Clin Proc. 1971;46(3):174-177.

11. Lin A, Feller ER. Pancreatic carcinoma as a cause of unexplained pancreatitis: report of ten cases. Ann Intern Med. 1990;113(2):166-167.

12. Saif MW, Khubchandani S, Walczak M. Secondary pancreatic involvement by a diffuse large B-cell lymphoma presenting as acute pancreatitis. World J Gastroenterol. 2007;13(36):4909-4911.

13. Wu CM, Cheng LC, Lo GH, Lai KH, Cheng CL, Pan WC. Malignant lymphoma of spleen presenting as acute pancreatitis: a case report. World J Gastroenterol. 2007;13(27):3773-3775.

14. Yoon WJ, Yoon YB, Kim YJ, Ryu JK, Kim YT. Primary pancreatic lymphoma in Korea - a single center experience. J Korean Med Sci. 2010;25(4):536-540. 